\title{
Apexification of Immature Teeth Using Novel Apical Matrices and MTA Barrier: Report of Two Cases
}

\author{
Dr.Pradnya Bansode ${ }^{1}$, Dr.Chetan Ahire ${ }^{2}$, Dr.Seema Pathak ${ }^{3}$, \\ Dr. Kundan Dekate ${ }^{4}$ \\ ${ }^{\text {I}}$ Professor and Head, Department of Conservative Dentistry and Endodontics, Govt. Dental College and \\ Hospital, Aurangabad(M.S), College, MUHS, India) \\ ${ }^{2,4}$ (Pg student, Department of conservative dentistry and endodontics, Govt. Dental College and Hospital, \\ Aurangabad(M.S), College, MUHS, India) \\ 3(Associate professor, Department of Conservative Dentistry and Endodontics Govt. Dental College and \\ Hospital, Aurangabad (M.S), College, MUHS, India)
}

\begin{abstract}
There are a number protocols to manage non-vital open-apex teeth such as apexification, apical barrier technique (one-visit apexification), orthograde root filling using MTA, triple antibiotic paste, and tissue engineering concept. Aim of this paper is to highlight the use of the novel materials such as PRF and DFDBA to be used as apical matrix in management of non vital open apex cases.
\end{abstract}

Keywords: Demineralized freeze dried bone allograft (DFDBA), MTA, open apex, Platelet rich fibrin (PRF), single step apexification,

\section{Introduction}

Traumatic injuries sustained before closure of the apex often results in immature pulpless teeth. In such situations, the absence of a natural constriction at the end of the root canal makes control of filling materials difficult [1]. Root canal rehabilitation is a significant challenge, because of the size of the canal, the thin and fragile dentin walls and the large open apex.

Apexification is defined as a method to induce a calcified barrier in a root with an open apex or the continued apical development of an incomplete root in teeth with necrotic pulp [2]. Apart from allowing compaction of the root filling material, the goal of this treatment also includes obtaining an apical barrier to prevent the passage of toxins and bacteria into the periapical tissues from the root canal.

Calcium hydroxide $(\mathrm{CH})$ has been the material of choice for apexification [3]. Calcific barrier formation is induced with repeated changes of material over the course of 5-20 months [4] averaging 12.9 months [5]. Some disadvantages of this technique have been reported. The lack of coronoradicular restoration and thus of an appropriate coronal seal makes the tooth susceptible to reinfection [6]. Prolonged contact with calcium hydroxide induces a significant decrease in the intrinsic properties of exposed dentin [7]. Repeated use of root canal irrigants like sodium hypochlorite, an organic solvent and chelating agent such as EDTA during treatment or to remove the calcium hydroxide after formation of apical barrier, result in further weakening of the dentin and render the tooth more prone to fractures These fractures occur frequently within 3 years of commencing treatment, with as many as $77 \%$ fractures in cases with least root development [8]. Mineral trioxide aggregate (MTA) is a FDA approved, commercially available material that has evoked considerable interest as a root end filling material. The granular consistency of the mix with sterile water makes the orthograde placement of the material in the apical region of canal technique sensitive.

Lemon [9] developed the internal matrix concept in which an intermediate layer of material is placed to form a barrier prior to placement of the repair material. The use of a matrix is advisable since its placement in the area of bone destruction provides a base on which the sealing material, especially MTA, can be placed and packed in the perforation [10-13] Several materials have been recommended to create a matrix, in cases of perforations as well as teeth with incomplete formation of apex; including calcium hydroxide, hydroxyapatite, resorbable collagen and calcium sulfate [11-16]. Materials such as Platelet rich fibrin (PRF), DFDBA (dimeralised freeze dried bone allograft) are widely used as graft material in periodontal and oral surgical procedures but not reported in literature to be used as apical matrix.

This article presents a detailed case series of the use of novel matrix such as Platelet rich fibrin (PRF), DFDBA (dimeralised freeze dried bone allograft), Hydroxyaptite prior to placement of MTA as an apical barrier. 


\subsection{CASE 1: PRF as apical matrix}

\section{CASE REPORTS}

A 14 years old male reported to the Dept. of Conservative Dentistry and Endodontics, GDC\&H, Aurangabad with the chief complaint of Occasional pain, swelling \& pus discharge in upper front region. On detailed history taking patient had traumatic incidence with same tooth before 6 years. Medical history of the patient was non-contributory. On clinical Examination incisal edge fracture with 21 and mild discolaration with 11 and 21 was noted. Tenderness was present on vertical percussion with 11 and 21. Access opening was seen with 11 and 21 which was done in private clinic. Radiographic Examination showed well defined periapical radiolucency with 11 and 21 along with Open apex and thin root dentinal wall with 21 (fig: 1A).

In the first visit the tooth \# 11 and 21 was isolated with rubber dam. After access cavity was refined, the cana was irrigated with copious $\mathrm{NaOCl}$ minimal instrumentation was done with \#80 K file to remove intracanal debris \& necrotic tissue, after working length determination. Calcium hydroxide in paste consistency was introduced till the CEJ level and the access cavity was sealed with temporary sealing material (MD Temp , META) in both incisors It was placed for the period of 21 days for canal disinfection.

At recall visit, under rubber dam isolation the tooth 21 was reopened and the calcium hydroxide was removed with copious saline irrigation and light instrumentation. The canal was dried with paper points. A plugger was selected \& adjusted short of the working length. Platelet Rich Fibrin (PRF) was prepared in Dept of oral pathology. After explaining the procedure to the patient $\&$ taking informed consent, $5 \mathrm{ml}$ of venous blood was withdrawn under all aseptic measures from Rt. forearm using $22 \mathrm{G}$ sterile needle \& syringe. The blood was immediately transferred to $5 \mathrm{ml}$ collection tube without any anticoagulants added to it \& immediately centrifuged to obtain PRF. Multiple small pieces of PRF were done with the help of sterile scissors to carry it into the apical region. Minute amount of MTA powder was sprinkled on the fibrin pieces to provide radiopacity for visualizing the placement of PRF (fig: 1B). The PRF was then carried with sterile cotton pliers inside the canal and was condensed gradually under radiographic guidance, using the controlled pressure with the help of pre-adjusted plugger (fig: 1C,D,E). MTA Angelus was then mixed with sterile water and placed over PRF matrix with the help of endodontic pluggers. 4 to $5 \mathrm{~mm}$ of apical plug of MTA was achieved over PRF (fig: 1F). MTA angelus sets within 15 minutes, setting of MTA was confirmed as a hard stop in canal with the help of plugger, Obturation of remainder space canal was done with the help of thermoplastic obturation system (E \& Q plus, Meta) Access opening sealing was done with composite resin (Matrix microhybrid) Root canal treatment of 11 (adjacent tooth) was performed in next visit. At 3 month and 6 month follow up satisfactory healing was seen in periapical region of 11 and 21 (fig: $1 \mathrm{H}$ ).

\subsection{CASE 2: DFDBA as apical matrix}

An 18-year-old male patient reported to the Department of Conservative Dentistry and Endodontics, GDC\&H Aurangabad, with a chief complaint of a discolored maxillary right central incisor. History revealed that the patient had suffered trauma at the age of 7 years and had received endodontic treatment from a private clinic. Clinical examination revealed discolored tooth no. 11, and access cavity preparation was previously done in the tooth. Radiographic examination revealed large periapical rarefaction and an incomplete formation of the root apex (fig: 2A). After the placement of rubber dam, the pulp chamber was cleaned and irrigated with $2.5 \%$ sodium hypochlorite. The walls of the canal were cleaned using a circumferential filing motion followed by an intracanal dressing with $\mathrm{Ca}(\mathrm{OH}) 2$ paste and sealing of the access cavity with temporary cement. (MD-Temp, Meta).

One week later, the tooth was again isolated under rubber dam and the canals thoroughly irrigated with saline to wash out any remnants of the $\mathrm{Ca}(\mathrm{OH}) 2$. DFDBA was mixed with normal saline to packable consistency. It was then carried to periapical area under radiographic guidance with the help of endodontic plugger having rubber stop at pre adjusted working length (fig 2B,C). After having confirmed adequate matrix mass of DFDBA, MTA angelus was mixed and placed over DFDBA with the help of messing gun to get compact plug of 3-4 mm (fig 2D). MTA plug was allowed to set for 15 minutes after which reminder of canal was obturated with thermoplastic gutta percha (E and Q plus, Meta) (fig 2E,F).. Access opening was sealed with composite resin (matrix microhybrid)

At 3 month and 6 month follow up healing in periapical area can be appreciated.

\section{DISCUSSION}

There are many methods recommended for artificial apical closure. Calcium hydroxide has been material of choice as an apexification material. Recently MTA has also been emerged strongly as artificial rootend closure material in open apices. Both materials were found to stimulate the formation of mineralized tissue, thereby providing an adequate seal in the apical region [17] MTA, a bio-compatible material, can be used to create a physical barrier that also helps in formation of bone and periodontium around its interface [1-5]. Although earlier studies recommended the use of a $\mathrm{Ca}(\mathrm{OH}) 2$ prior to MTA placement, recent studies report that 
the initial use of $\mathrm{Ca}(\mathrm{OH}) 2$ paste was not necessary for apexification to occur, and it has shown to be strongly related to the extrusion of MTA and formation of barriers beyond the limits of the root canal walls. 3 The major problem in cases of a wide open apex is the need to limit the material to the perforation, thus avoiding the extrusion of a large amount of material into the periodontal tissue [18,19]. A large volume of the extruded material may set before it disintegrates and get resorbed. This might result in the persistence of the inflammatory process, which may complicate or even prevent repair of the tissue $[18,19]$ Using a matrix avoids the extrusion of the material into the periodontal tissues, reduces leakage in the sealing material and allows favorable response of the periodontal tissues. As mentioned before, a number of materials are available for the formation of the apical matrix.

In frist case Platelet Rich Fibrin (PRF) is used as an autogenous, cost-effective and resorbable internal matrix prior to placement of MTA as an apical barrier. Platelet-rich fibrin (PRF) represents a new step in the platelet gel therapeutic concept with simplified processing without artificial biochemical modification. Unlike other platelet concentrates, this technique requires neither anticoagulants nor bovine thrombin nor any other gelifying agent making it no more than centrifuged natural blood without additives [20] The real therapeutic potential of PRF lies in Platelet alpha $(\alpha)$ granules form an intracellular storage pool of growth factors (GF) including platelet-derived growth factor (PDGF), transforming growth factor $\beta$ (TGF- $\beta$, including $\beta-1$ and $\beta-2$ isomers), vascular endothelial growth factor (VEGF), and epidermal growth factor (EGF).7 Insulin-like growth factor-1 which accelerate rate of healing [21].

In second case DFDBA was used as apical matrix. DFDBA is obtained from cortical bone of long bones due to its high content of bone inductive proteins and less antigenic activity than cancellous bone. The collagen matrix present in DFDBA acts as a scaffold that provides osteoconductive properties alone side the osteoinductive behavior [22]. BMPs are associated with the organic matrix of bone and embedded within mineral content, so demineralised process in formation of DFDBA increases its bioavailability. BMPs attract mesenchymal stem cells and induce them to differentiate into chondrocytes leading into endochondral bone formation [23] This property is helpful in healing of large periapical lesions. Taking into consideration all these advantages of PRF and DFDBA, we have used these materials as an apical barrier matrix over which MTA, a well known root end filling material was placed proving success of this case.

\section{Conclusion}

The use of PRF and DFDBA as a matrix and MTA has been demonstrated to be a good option for creating artificial root-end barriers. The placement of MTA is predictable over these matrices and the outcomes are very encouraging.

\section{REFERENCES}

[1] Seltzer S. Endodontology: Biologic Considerations in Endodontic Procedures, 2nd edn. Philadelphia: Lea \& Febiger, 1988.

[2] American Association of Endodontists Glossary of Endodontic Terms, 7th edn. Chicago: American Association of Endodontists, 2003.

[3] Rafter M. Apexification: a review. Dent Traumatol 21: 1-8, 2005.

[4] Sheehy EC, Roberts GJ. Use of calcium hydroxide for apical barrier formation and healing in nonvital immature permanent teeth: a review. Br Dent J, 183: 241-6, 1997.

[5] Dominguez Reyes A, Munoz Munoz L, Aznar Martin T. Study of calcium hydroxide apexification in 26 young permanent incisors. Dent Traumatol, 21: 141-5, 2005.

[6] Lolayekar N, Bhat SS, Hegde S. Sealing ability of ProRoot MTA and MTA-Angelus stimulating a one-step Apical barrier technique - an in vitro study. J Clin Pediatr Dent, 33(4): 305-310, 2009.

[7] Andreasen JO, Farik B, Munksgaard EC. Long-term calcium hydroxide as a root canal dressing may increase risk of root fracture. Dent Traumatol, 18: 134-7, 2002.

[8] Cvek M. Prognosis of luxated non vital maxillary incisors treated with calcium hydroxide and filled with gutta percha. A retrospective clinical study. Endodontics and Dental Traumatology, 8: 45-55, 1992.

[9] Lemon RR. Nonsurgical repair of perforation defects. Internal matrix concept. The Dental Clinics of North America, 36: 439-57, 1992.

[10] Rafter M, Baker M, Alves M, Daniel J, Remeikis N. Evaluation of healing with use of an internal matrix to repair furcation perforations. Int Endod J 2002;35:775-83.

[11] Al-Daafas A, Al-Nazhan S. Histological evaluation of contaminated furcal perforation in dogs teeth repaired by MTA with or without internal matrix. Oral Surg Oral Med Oral Pathol Oral Radiol Endod 2007;103:92-9.

[12] Jantarat J, Dashper SG, Messer HH. Effect of matrix placement on furcation perforation repair. J Endod 1999;25:192-6.

[13] Bargholz C. Perforation repair with mineral trioxide aggregate: A modified matrix concept. Int Endod J 2005;38:59-69

[14] Mesimeris V, Sade E, Baer PN. Calcium sulfate as a biodegradable barrier membrane: A preliminary report on the "Surgiplast" technique. Periodontal Clin Invest 1995;17:13-6.

[15] Alhadainy HA, Himel VT, Lee WB, El Baghdady YM. Use of a hydroxylapatite-based material and calcium sulfate as artificial floor to repair furcal perforations. Oral Surg Oral Med Oral Pathol Oral Radiol Endod 1998;86:723-9.

[16] Zou L, Liu J, Yin SH, Tan J, Wang FM, Li W, et al. Effect Of placement of calcium sulphate when used for repair of furcation perforation on seal produced by a resin-based material. Int Endod J 2007;40:100-5.

[17] Holden DT, Schwartz SA, Kirkpatrick TC, Schindler WG. Clinical outcomes of artificial root-end barriers with mineral trioxide aggregate in teeth with immature apices. J Endod 2008;34:7:812-7.

[18] Broon NJ, Bramante CM, Assis GF, Bortoluzzi EA, Bernardineli N, Moraes IG, et Healing of root perforations treated with mineral trioxide aggregate (MTA) and Portland cement. J Appl Oral Sci 2006;14:305-11. 
[19] Holland R, Mazuqueli L, Souza V, Murata SS, Dezan E Jr. Influence of the type of vehicle and limit of obturation on apical and periapical tissue response in dogs teeth after root canal filling with mineral trioxide aggregate. J Endod 2007;33:693-7.

[20] Su CY, Kuo YP, Tseng YH, Su C-H, Burnouf T. In vitro release of growth factors from platelet-rich fibrin (PRF): a proposal to optimize the clinical applications of PRF. Oral Surg Oral Med Oral Pathol Oral Radiol Endod 2009; 108:56-61

[21] Dohan DM, Choukroun J, Diss A, Dohan SL, Dohan AJ, Mouhyi J, et.al. Platelet-rich fibrin (PRF): a second-generation platelet concentrate. Part I: technological concepts and evolution. Oral Surg Oral Med Oral Pathol Oral Radiol Endod 2006; 101:e37-44.

[22] Drosos GI, Kazakos KI, Kouzoumpasis P \& Verettas DA.(2007). Injury;38 Suppl 4:S13-21.

[23] Esposito M, Piattelli M, Pistilli R, Pellegrino G. \& Felice P.(2010). Eur J Oral Implantol;3(4):297-305.

\section{LEGENDS OF FIGURES}

Case 1-

1A -Pre operative radiograph

1B- Small pieces of PRF prepared from patients own blood

1C-Placement of PRF inside root canal of 21

1D-Radiograph showing pushing PRF in periapical area with endodontic plugger of 21

1E- Radiograph showing completely pushed PRF in periapical area of 21

1F-Radiograph immediately after placement apical plug of MTA with 21

1G-Radiograph at 3 months follow up

1H-Radiograph at 6 months follow up showing satisfactory healing in periapical region of 11 and 21
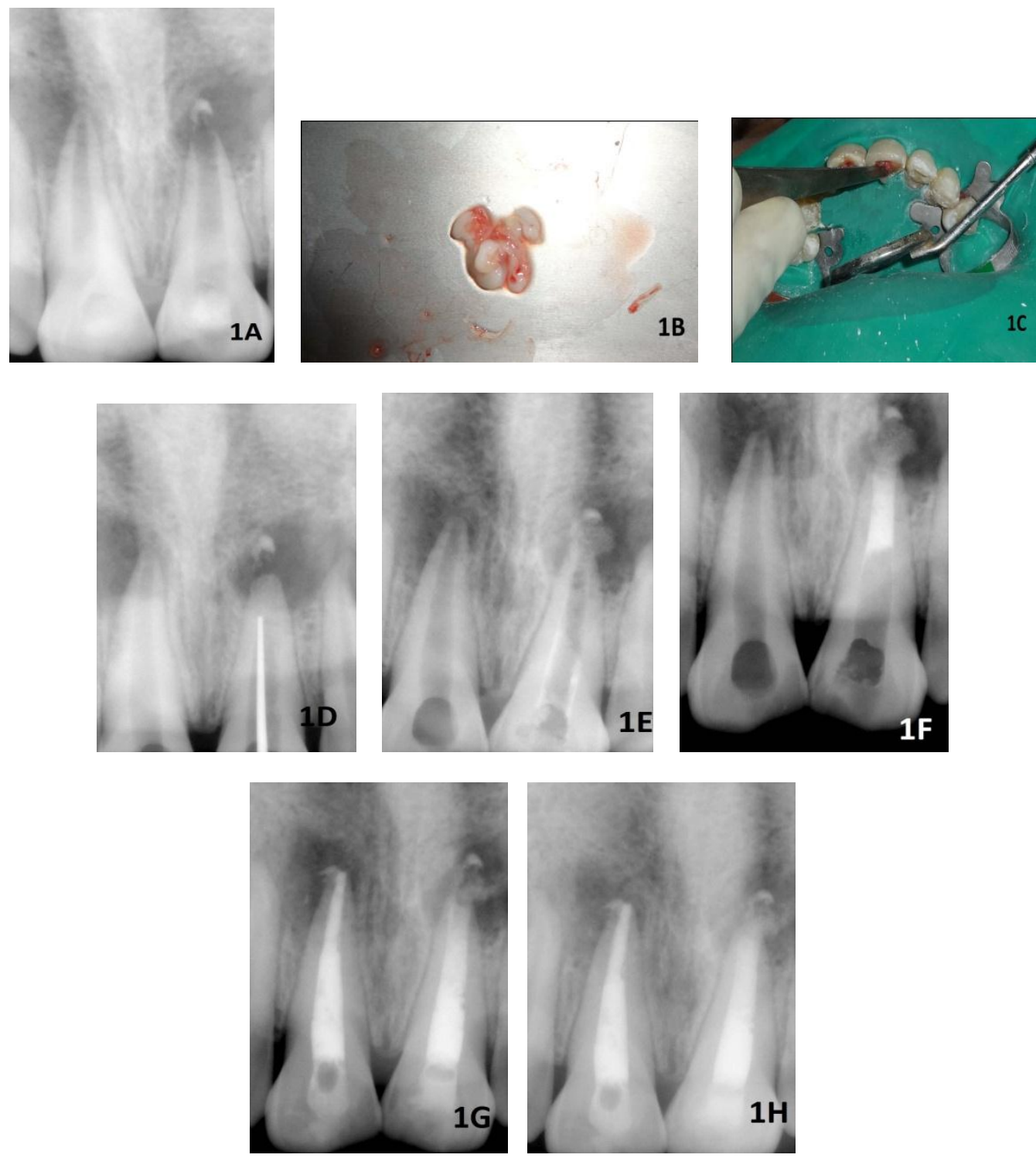
CASE 2

2A -Pre operative radiograph

2B- Radiograph showing endodontic plugger to pre adjusted working length with 11

2C- Radiograph showing pushing DFDBA in periapical area with endodontic plugger of 11

2D- Radiograph immediately after placement apical plug of MTA and obturation with 11

2E-Radiograph at 3 months follow up

2F-Radiograph at 6 months follow up showing satisfactory healing in periapical region of 11
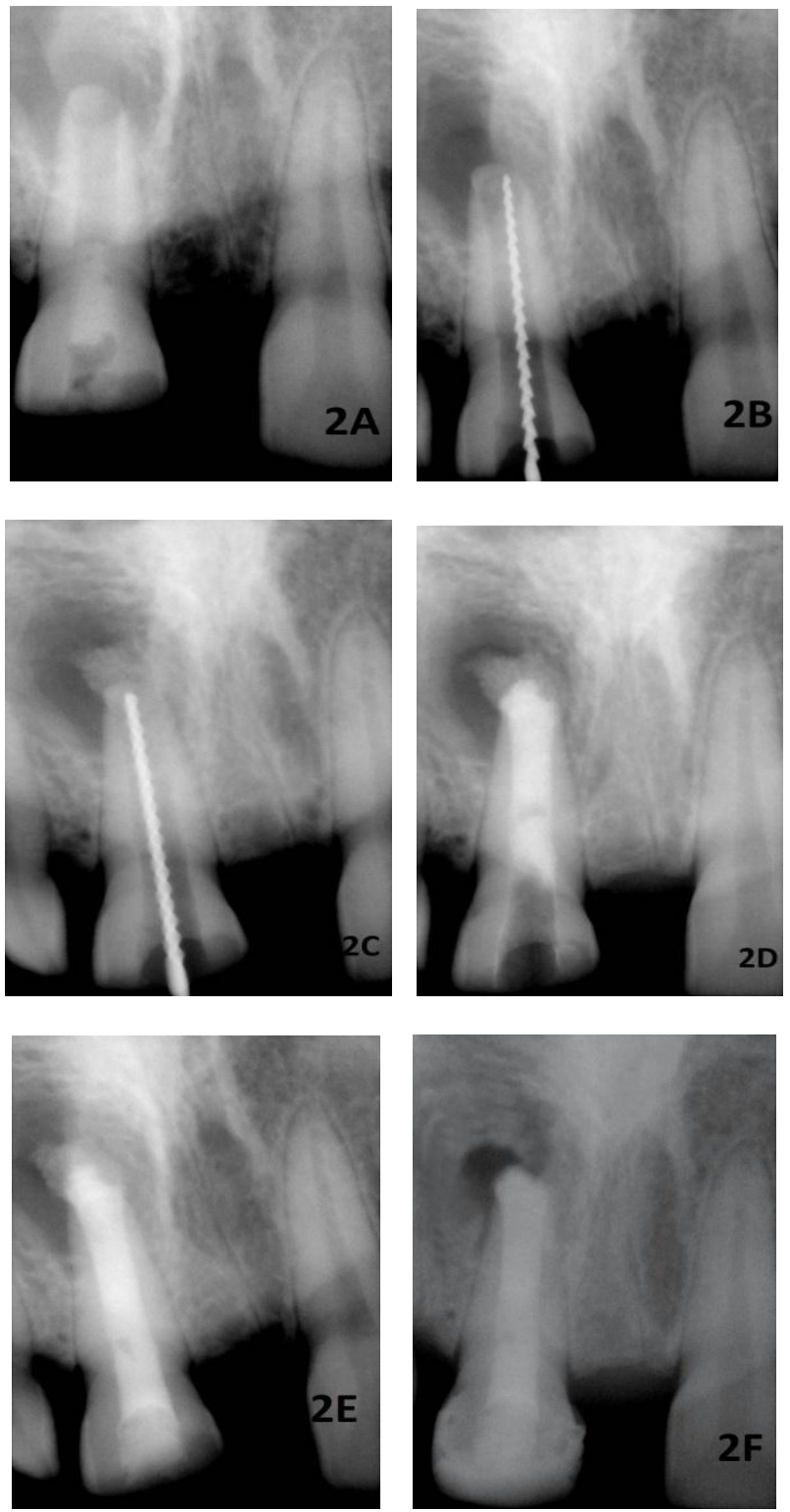